\title{
O ACENTO LINEAR EM PORTUGUÊS
}

\author{
José Baltazar Teixeira
}

RESUMO: The article presents a new purpose, starting by defining suprasegmental elements, in which the study of the accent is included, and also inserting it simultaneously between two criteria that have been postulated as heterogeneous. It presents the natural gerative phonology model, which seeks a major "linguistic realism", explaining accent through a morphophonemic process and evaluating it in a less mathematical way than the transformational one. Chomsky/Halle model seeks a great formal simplicity in the formulation of the rules, making use of some devices in dealing with exceptions. The article includes some criticism to that analysis, in which Botha (1971) discusses the value of those devices with no phonetical use created to "produce expected effects" in an "ad hoc" way.

PALAVRAS-CHAVE: Chomsky/Halle, Troubetzkoy, Botha, elementos supra-segmentais, acento.

O estudo do acento está incluído, tradicionalmente, entre o estudo dos elementos chamados de supra-segmentais:

O conceito de elemento supra-segmental pode ser compreendido levando em conta dois critérios. Ora um é colocado em primeiro plano, ora outro. Os critérios são:

a) considerando o ponto de vista articulatório, elementos suprasegmentais se pronunciam simultaneamente com os segmentos da língua. Sua pronúncia superpõe-se à dos segmentos e não altera as propriedades básicas destes;

b) considerando o ponto de vista de uma análise fonológica, é importante ressaltar que os elementos supra-segmentais sempre exigirão uma referência a unidades maiores do que o segmento, isto é, sílaba, palavra e frase. Nesse caso, os traços suprasegmentais não pertencem ao inventário de traços de um segmento, mas sim pertencem a uma unidade maior.

Que elementos lingüísticos podem ser analisados como suprasegmentais? Não há concordância quanto a esse aspecto e as opiniões 
divergem. Tal situação é devida ou ao fato de que em modelos teóricos diferentes é dado peso diferente aos dois critérios ou ao fato de que um desses critérios é excluído. Em uma análise fonêmica tradicional, tal como proposta por Pike, o critério (a) é o mais importante. Sendo assim, o acento, o tom e a duração vão ser analisados como fonemas supra-segmentais. Pike os 


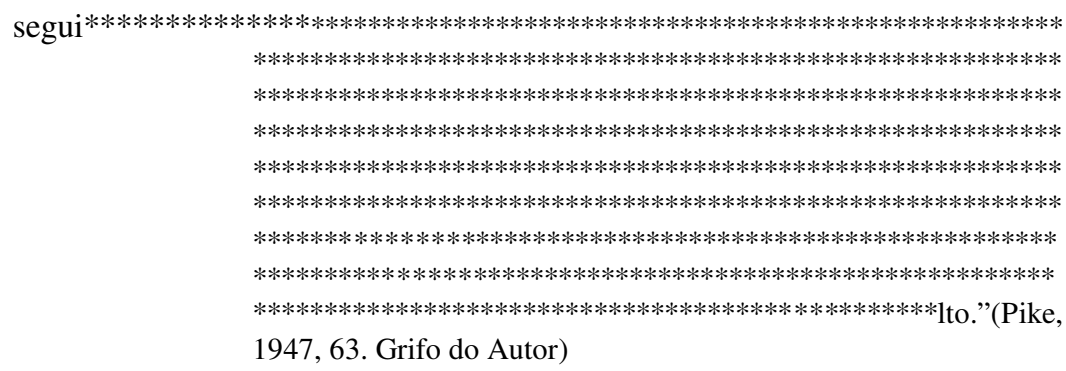

Larry Hyman no seu livro Phonology - Theory and Analysis, propõe que o acento, o tom e a duração representam um subgrupo entre os elementos supra-segmentais e os denomina supra-segmentais de proeminência. Por outro lado, quaisquer traços cuja análise implique em ter como ponto de referência unidades maiores do que o segmento são incluídos entre os elementos suprasegmentais.

Por exemplo, tratar a nasalização como supra-segmental em línguas onde há uma harmonia nasal dentro da sílaba. Outro exemplo seriam os casos de harmonia vocálica que poderiam ser analisados como elementos suprasegmentais.

O caráter de proposta renovadora deve ser sublinhado no trabalho de Hyman, já que elimina o primeiro critério, mais tradicional na definição de elementos supra-segmentais. Contudo, com base em (a), define-se na análise de Hyman, um subgrupo entre elementos que foram selecionados, previamente, com base em (b).

Em se tratando de acento de intensidade, a análise de Hyman precisa levar em conta uma sequiência de segmentos. O acento, então, incidirá em unidades maiores do que o segmento. Tais unidades são as sílabas, na grande maioria das línguas, ou, então, as moras em algumas línguas. Em uma seqüência dessas unidades, delimitada a partir de critérios gramaticais, o acento só ocorrerá em uma unidade de sequiência. Levando, então, em conta o que dissemos até agora em relação ao acento, poder-se-á concluir que o acento é uma traço supra-segmental cujo funcionamento se dá de acordo com os dois sentidos aludidos, isto é, (a) e (b). De acordo com estas duas posições, o acento ocorre no máximo uma vez dentro da palavra e é produzido simultaneamente com o segmento, gerando aumento de amplitude da onda sonora sem alterar sua qualidade básica.

Análise em direção mais ou menos oposta pode ser encontrada em Garde, Paul (1968). Para ele, o estudo do acento precisa ser iniciado com uma pergunta: pode o acento ser considerado um traço distintivo? No caso de resposta afirmativa, será possível ter, em uma língua qualquer, dois fonemas distintos: /a/ e /á/. A interpretação do traço de acento, no caso, será a de considerá-lo como da mesma natureza que traços de altura, de arredondamento, etc. Impõe-se a pergunta: é esta a análise adequada ao estudo do acento? A resposta, conforme Garde, tem como ponto de partida 
uma divisão tipológica das línguas segundo o acento: línguas com acento fixo e línguas com acento livre. Nas línguas do primeiro tipo, a posição do acento é sempre em uma sílaba determinada, contada a partir do princípio ou do fím da palavra. Nesta situação, não é possível considerar o acento como traço distintivo, mas sim como um traço redundante e, por isso mesmo, previsível a partir do contexto. Nas línguas do segundo tipo, isto é, com acento livre, existe a possibilidade de que ele seja considerado um traço distintivo, pois ele preenche uma função distintiva.

As idéias de Paul Garde compõem a sua teoria universal do acento. Nesta perspectiva, é proposta a existência de unidades acentuáveis, não obrigatoriamente sílabas, bem como a existência de unidades acentuais que não coincidem, necessariamente, com as palavras. Garde introduz, com bastante clareza, a noção de mora que deve ser entendida como toda parte de sílaba capaz de receber acento por si mesma. Essa noção implica na possibilidade de mudança de acento não só de uma sílaba a outra, mas também de uma parte de sílaba a outra. Sílaba e mora constituem, então, as assim chamadas unidades acentuáveis e contrastam entre si pelo uso do acento.

Quanto às unidades acentuais, dir-se-á que são unidades dentro das quais o contraste de acento é criado. Este conceito de unidades acentuais aproxima-se da noção de palavra. A definição proposta para uma unidade acentual seria: uma unidade significativa maior do que o morfema e menor do que a frase.

Defender a inclusão do acento no inventário de traços distintivos é uma hipótese rejeitada por Garde na medida em que é possível definir o acento por sua função. Esta, tanto em línguas de acento livre quanto em línguas de acento fixo, é sempre a mesma. É uma função denominada contrastiva que não se identifica com a função distintiva. Ela ocorre no plano paradigmático, enquanto a função contrastiva é observada no plano sintagmático pela confrontação de pontos sucessivos de uma seqüência. A realização da função distintiva no plano paradigmático pode ser ilustrada através do confronto dos segmentos $/ \mathrm{p} / \mathrm{b} /$ do português, por exemplo, em pala/bala .

Ao contrário, por ser contrastiva, a função do acento se exerce sintagmaticamente, o que significa que a presença do acento em uma sílaba implica na sua ausência nas outras sílabas. Vê-se, portanto, que o acento não está em oposição com a ausência de acento em um ponto qualquer do enunciado. A análise dos traços distintivos exige que observemos um mesmo ponto em diversas seqüências. O contrário se dá no contraste acentual, porquanto atua entre vários pontos sucessivos de uma unidade maior, cujos critérios de definição são gramaticais.

De maneira geral, para que se realize o estudo do acento nas línguas, três etapas devem ser obedecidas. A primeira seria delimitar segmentos contrastáveis, entre si, pelo acento. Tais segmentos não são unidades 
significativas e sua delimitação é feita observando critérios fonológicos: a sílaba ou a mora.

A segunda etapa estabelece seqüências em cujo interior é criado o contraste acentual. Aquelas são unidades significativas, identificadas por meio de critérios gramaticais e se aproximam da delimitação de palavras.

A terceira, por fim, é o estabelecimento da posição do acento, o que significa, em geral, a determinação da sílaba que recebe o acento, dentro da palavra. E nesta etapa surge, para fins de colocação de acento, a questão da línguas que têm acento fixo e as que têm acento livre. Para as primeiras, a sílaba que recebe o acento é determinada apenas por critérios fonológicos. As do segundo tipo, de acento livre, terão o estabelecimento das sílabas acentuadas através de critérios gramaticais.

A teoria de Garde propõe dois tipos de procedimento, quando discute a função que tem o acento de estabelecer um contraste entre sílaba acentuada e as outras não acentuadas dentro de uma palavra. São procedimentos de natureza positiva e procedimentos de natureza negativa. Procedimentos positivos acrescentam um traço à sílaba acentuada ao passo que os de natureza negativa são responsáveis pela perda de uma possibilidade distintiva fora do acento. Traços acrescentados são do tipo intensidade (força expiratória), tom (altura musical) e duração (espaço de tempo em que o som é pronunciado). Traços retirados da língua, pelos procedimentos acentuais negativos, são traços que pertencem ao inventário de traços distintivos da língua.

Reconhecer procedimentos acentuais é reconhecer que existem certos processos fonológicos motivados pelo acento e entre tais processos, um leva à diminuição das possibilidades distintivas em sílabas não acentuadas.

Para concluir esta apresentação, de caráter geral de algumas idéias de Paul Garde, é interessante a comparação com a posição de Troubetzkoy no que diz respeito à função do acento. Para Garde, como vimos, a função do acento é a mesma em línguas com acento fixo e em línguas com acento livre, enquanto que Troubetzkoy distingue a função conforme o tipo de língua. A função contrastiva de Garde recebe a denominação de função culminativa no trabalho de Troubetzkoy. E é essa a função do acento naquelas línguas cujo acento é livre.

Por outro lado, em línguas com acento fixo, a função do acento é a de ser um signo demarcativo, marcando o princípio ou o fim de uma unidade significativa. Vê-se, então, que essa função acentual está muito próxima à de certos processos fonológicos que ocorrem em fronteiras de palavras.

A situação em português é analisada por Câmara Jr., que propõe uma dupla função para o acento. A primeira é de natureza distintiva. Essa função aparece na diferenciação de diversos pares de palavras pela posição do acento. A segunda função seria a de demarcar, na corrente sonora os vocábulos fonológicos. Não sendo o português uma língua de acento fixo, 
resulta evidente que o acento primário pode marcar a existência de um vocábulo fonológico. Não marca, porém, os seus limites na cadeia sonora.

A definição de acento de Câmara Jr. é força expiratória relativa de uma sílaba. Para o português, vê o acento dentro de uma escala de intensidade que comporta quatro níveis significativos: 0, 1, 2 e 3 distribuídos em escala crescente de força expiratória. A vogal de emissão mais forte, exatamente pela diferença de intensidade na realização dessas articulações, vai contrastar com as demais.

Para Mattoso o acento é distintivo em português, porquanto existem palavras, na língua, cuja diferenciação depende da posição da sílaba tônica: se a posição do acento é o único elemento que distingue algumas palavras entre si no português, então o acento tem uma função distintiva. Essa função é acumulada, ainda segundo Mattoso, com uma outra: função delimitativa. Esta possibilita o assinalamento do assim chamado vocábulo fonológico dentro do contínuo da fala. Assim sendo, a presença de um acento de grau 2 ou 3 salienta a presença de um vocábulo fonológico. Dentro de um vocábulo fonológico, não há possibilidades de se prever o acento, mas apenas uma área acentuável que engloba as quatro últimas sílabas do vocábulo é prevista pela regra de acento proposta por Mattoso. Os graus de atonicidade , que são dois, são previstos, dentro do vocábulo fonológico, levando em consideração a posição em relação à sílaba de acento mais forte. $\mathrm{O}$ grau 2 de tonicidade também é previsível dentro do grupo de força.

Se os níveis de atonicidade e subtonicidade são previsíveis a partir do contexto, tal não acontece com a tonicidade e Câmara Jr. afirma que a tonicidade não é previsível dentro do vocábulo. A constituição fonológica de cada palavra não é responsável pela posição de acento mais forte. Certas terminações apresentam uma freqüência maior de um padrão acentual. Isto, porém, não significa que existam, em português, terminações de fonemas que imponham uma dada acentuação.

Apenas o nível mais forte de acento não é previsível na palavra. Se ele for tomado como ponto de referência, será possível, tendo-o como ponto de partida, determinar os graus de intensidade das outras sílabas. Em caso de haver grupo de força, o último acento manter-se-á no nível 3 e os outros acentos tônicos enfraquecerão para 2.

Por outro lado, é preciso salientar que os graus de acento 1 e 0 indicam em que ponto se dá a juntura de palavras dentro de um grupo de força, o que lhes confere um outro tipo de função delimitativa. Esse fato pode ser encontrado em Leite (1974), observando a análise de determinados pares de seqüências. A saber:

ar demais $\left[\begin{array}{llllllll}\sigma & \Omega & H & H & O & \sigma & \square & \bullet\end{array}\right]$ arde mais $[\sigma \quad \Omega \quad H[C]$

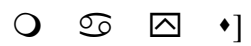

$2 \quad 1 \quad 3$
$2 \quad 0 \quad 3$ 


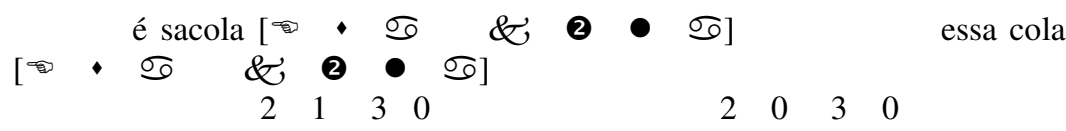

Diretamente ligada à questão das vogais não-acentuadas, está o processo de neutralização. Mattoso utiliza o conceito tal qual proposto por Troubetzkoy: fora do acento, as possibilidades distintivas diminuem e para cada dois ou mais fonemas resta apenas um, havendo uma redução do número de fonemas.

Dentro de uma perspectiva taxonômica, é possível pensar o acento como um tipo de fonema, ou seja, um fonema supra-segmental. Segundo a proposta de Leite (1974) que se vale de princípios da análise taxonômica, o acento é fonêmico em português, porquanto existem pares de palavras que só se diferenciam pela posição do acento. No trabalho citado, a autora aponta um paralelismo na distribuição entre vogais tensas e acento. A saber: todas as sílabas acentuadas têm vogais tensas (i, e, $\square, a, 2 \backsim 0, u)$ e as nãoacentuadas apresentam vogais não-tensas. É uma situação, em português, que possibilita duas alternativas de análise: interpretar as vogais tensas como fonêmicas e o acento condicionado à presença dessas vogais, conseqüentemente não-fonêmico. A segunda alternativa é propor o acento como fonêmico, propondo para cada vogal um alofone tenso e outro nãotenso. O primeiro ocorrendo em ambiente acentuado e o segundo em ambiente não acentuado.

Ao que tudo indica, taxonomicamente existem dois motivos para optar pela análise que considera o acento como fonêmico. Em primeiro lugar, trata-se de uma interpretação mais econômica, já que apresenta um menor número de fonemas do que a outra; isto é, apenas oito fonemas: sete vogais e o acento, em vez de doze fonemas. Isto no tocante às vogais orais. Em segundo lugar, problemas serão evitados na análise das vogais nasais que não apresentam o tipo de distribuição destacado entre vogais tensas e não-tensas, conforme o acento.

\section{O ACENTO NO MODELO DA FONOLOGIA GERATIVA TRANSFORMACIONAL}

Regras cíclicas são, em especial, as que vão determinar os diversos níveis de acento e o contorno de entonação.

A proposta que Chomsky \& Halle (1968) defendem para a regra do acento, em inglês, é de que ele não seja incluído na matriz de um item lexical, mas seja previsto por regras.

Inclusão de acento na matriz de um item lexical implica que uma das primeiras regras do componente fonológico atue atribuindo a cada segmento, e a cada fronteira, a especificação de traço [-Ac]. Essa especificação será substituída por índices de acento, em certas posições, em segmentos vocálicos, mas não em consoantes e fronteiras. Esses índices representam 
diversos graus de intensidade na emissão das vogais. Tais graus são o correlato articulatório e perceptual dos índices. Por outro lado, é preciso observar que índices de acento refletem a situação de que na análise do acento é levada em conta não uma oposição binária - presença e ausência de uma característica articulatória - mas uma escala de vários níveis relativos de intensidade.

A formalização Chomsky/Halle apresenta uma escala que parte do mais forte (Ac 1) para o mais fraco (Ac 2, Ac 3, ... Ac n). É convencionalmente assumido que todos os índices de acento representam subdivisões da categoria [ +Ac ]. Conforme vimos, segmentos e fronteiras pertencem, por atribuição de regra, à categoria [-Ac ]. Quando a um segmento vocálico é atribuído o traço [ Acn ] (onde $\mathrm{n}$ significa um índice qualquer de acento), tal segmento passa a pertencer à categoria [+Ac ]. As representações [ +Ac ] e [ -Ac ] são utilizadas como termos de cobertura para maior facilidade na formulação das regras fonológicas. Uma sequiência de unidades especificada como [ -Ac ] incluirá vogais, consoantes e todos os tipos de fronteiras. Estamos diante de um tratamento uniforme que reflete o fato de ser o acento um traço prosódico, cujo domínio se estende sobre sequiências maiores do que uma palavra.

\section{Representações fonológicas dos sons do português. Algumas realizações fonéticas das vogais}

Processos de enfraquecimento de vogais associados aos graus de acento.

\section{$O$ acento nos nomes e adjetivos}

Tecnicamente, é possível entender o acento como uma característica inerente à matriz lexical dos morfemas do português. No entanto, em nenhuma análise da língua essa possibilidade é explorada. Em relação ao acento primário, e em qualquer classe, há mais regularidades do que irregularidades. O que estaria significando, então, que aqueles casos que constituem uma minoria de irregularidades, se analisados, produziriam uma análise simples geral.

Dentro da teoria gerativa, os trabalhos que tratam do acento em português insistem em dois pontos. A saber: (1) a regra de acento deve ser uma das primeiras em ordenação; (2) o acento na grande maioria das palavras do português deve ser colocado por uma regra geral, que insere o acento primário na penúltima vogal da palavra. Para que se consiga essa regularidade na acentuação da maior parte das palavras da língua por uma só regra, a (grande) maioria das representações subjacentes terá de apresentar segmentos que não aparecem nas representações fonéticas. Esses segmentos são apagados por uma regra depois da colocação do acento. Essa é a situação que justifica a aludida ordenação como uma das primeiras da regra de acento. 
De acordo, então, com o exposto, palavras oxítonas, falsas oxítonas, terão uma representação subjacente com uma sílaba a mais do que na realização fonética, o que lhes permitirá receber o acento regularmente segundo a regra geral. Exemplificando, temos:

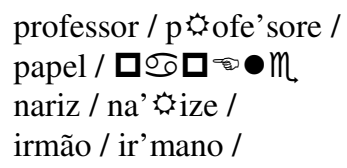

Representações fonológicas desse tipo são sugeridas em Abaurre (1973) e Bastelli (1975), e em vários outros trabalhos.

A presença de um segmento a mais na representação subjacente torna possível encontrar uma regularidade mais profunda no padrão acentual de dois grupos de palavras oxítonas: as terminadas foneticamente em consoantes e em ditongo nasal.

Palavras oxítonas terminadas em vogal são marcadas no léxico, por um traço diacrítico que as assinala para a aplicação de uma regra especial de acentuação. Assim propõe Abaurre (1973). Segundo a autora, o uso de uma análise que lance mão da estratificação lexical possibilitaria que palavras de origem erudita fossem analisadas como tendo a mesma raiz que suas correspondentes de origem vulgar. Exemplos poderiam ser as eruditas pedestal, crédito, legível cujas raízes seriam pé, crer, ler. Os formativos das eruditas seriam marcados com $[+\mathrm{E}]$ diacrítico que estaria a indicar tratar-se de formativos especiais. A eles aplicar-se-ia um grupo de regras do componente fonológico com atuação só sobre a porção do léxico assinalada com esse diacrítico.

O mesmo conceito, isto é, a estratificação lexical, é proposto por Abaurre para explicar, também, o acento das palavras terminadas em vogal. Torna-se, portanto, evide $* * * * * * * * * * * * * * * * * * * * * * * * * * * * * * * * * * * * * * * * * * * * * * * * * * * * * * * * * * * * *$

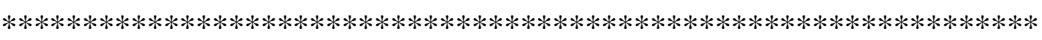

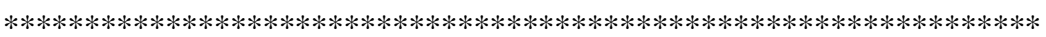




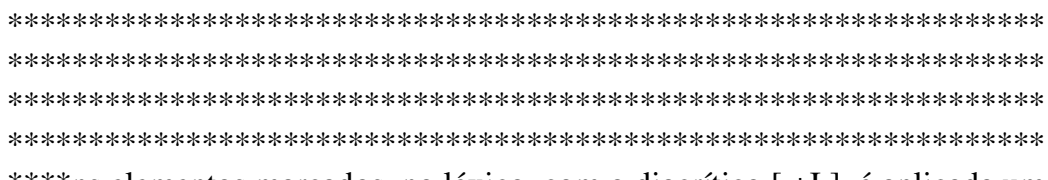

****ns elementos marcados, no léxico, com o diacrítico [ +I ], é aplicada uma regra especial que insere o acento primário na última vogal.

Vejamos, agora, alguns aspectos do tratamento que o modelo propõe para as palavras proparoxítonas. Em um primeiro momento, há duas alternativas. A saber: ou têm de ser marcadas, também, com um diacrítico no léxico que está a indicar que a regra geral de acento não se aplica a elas, ou vai ser preciso propor mais uma traço para a representação fonológica das vogais. Tal traço seria o tenso, cuja possibilidade de uso vem aventada, também, em Abaurre (1973).

Em uma perspectiva de comparação, examinemos alguns pontos da análise que Harris (1969) propõe para o acento em espanhol usando o traço de tensão nas vogais. Segundo Harris, a regra de acento do latim explica o acento dos nomes do espanhol. Esta regra se aplica primeiro em sua forma mais completa, isto é, na seguinte configuração:

$1^{\text {a }}$. expansão da regra de acento do latim:

$\left.\mathrm{V} \rightarrow[\mathrm{Ac} 1] /{ }_{-} \mathrm{C}_{\mathrm{o}} \mathrm{V} \mathrm{C}^{1}{ }_{\mathrm{o}}(\mathrm{L}) \mathrm{V} \mathrm{C} \#\right] \mathrm{N}$, Adj

Harris usa, na formulação das suas regras, o traço de tensão para as vogais. Já se viu que existem diferenças na tensão das vogais do português, em nível fonético, que correlacionam com diferenças na altura e no grau de acento. A utilização desse traço nas regras de acento do português exigiria que ele fizesse parte dos traços distintivos. Se assim for feito, acarretará na duplicação do número de segmentos vocálicos propostos para a representação subjacente, isto é, para cada vogal haveria uma representação [ + tensa ] e outra [ - tensa ]. Na verdade, o uso desse traço estaria funcionando como um diacrítico, ou seja, marcar certas vogais da penúltima sílaba de algumas palavras para que não recebam o acento primário. Estaríamos diante do uso indevido de um traço fonológico, uma vez que lhe é atribuído uma função diacrítica. Assim sendo, é natural, perguntar por que não trabalhar diretamente com diacríticos.

Diante desta situação, a proposta que surge é: usar traços diacríticos para a análise das proparoxítonas. E o argumento a sustentar tal solução pode assim ser entendido: como os nomes e adjetivos proparoxítonos constituem minoria na língua e como já foi indicado que para analisar os nomes oxítonos será necessário fazer uso de traços diacríticos, nada mais natural do que estender esta análise também aos proparoxítonos.

São propostas para o português duas regras de acento: uma para o caso especial dos oxítonos, na sua maioria de origem indígena, e mais uma regra geral. Esta última constitui-se em um conjunto de três regras 
disjuntivamente ordenadas e que se aplicam segundo o pricípio de ordenação disjuntiva. A saber:

$$
\begin{aligned}
& \text { Regra de acento dos oxítonos } \\
& \mathrm{V} \rightarrow[\text { Ac 1 }] / I_{-} \text {] N, Adj }
\end{aligned}
$$

Usar-se-á o diacrítico [ +E ] para marcar as palavras proparoxítonas para a aplicação da regra de acento. Porque têm um comportamento semelhante ao dos nomes e adjetivos em relação ao acento, incluem-se os advérbios na formulação da regra.

Regra geral de acento dos nomes, adjetivos e advérbios

\section{O acento nos verbos}

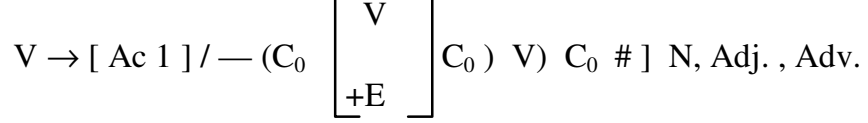

Os verbos não devem ser acentuados pela mesma regra que foi proposta para nomes e adjetivos. Assim, a regra de acento dos verbos precisa ser formulada de maneira diferente do que foi feito para nomes e adjetivos.

Segundo Harris, conforme sua proposta para o espanhol, a regra segundo a qual o acento deve recair sobre a penúltima vogal de análise é aceita também por Abaurre (1973) como válida para os verbos do português. A formulação dessa regra de acento para os verbos é:

$$
\left.\mathrm{V} \rightarrow[\text { Ac } 1] /-\mathrm{C}_{0} \mathrm{~V} \mathrm{C}_{0} \#\right] \mathrm{V}
$$

Várias formas verbais apresentam problemas para a colocação do acento por essa regra. A discussão dessas formas bem como os obstáculos ao uso da regra estão fora do nosso propósito no momento. Não obstante, achamos interessante remeter ao trabalho de Costa (1978) onde no capítulo Análise do acento segundo a fonologia gerativa transformacional são discutidas, na sua grande maioria, as questões relacionadas com a aplicação da regra.

Após longas discussões, nas quais são examinadas propostas para o funcionamento da regra, surge a reformulação da regra de acento dos verbos, cujo resultado é o seguinte:

$$
\mathrm{V} \rightarrow[\text { Ac 1 }] /-\left(\left(+\left[\begin{array}{l}
- \text { perfectivo } \\
+ \text { perfectivo } \\
+ \text { anterior }
\end{array}\right]\right) \mathrm{C}_{0} \mathrm{~V}\right) \mathrm{C}_{0} \#
$$

Esta regra em sua forma mais reduzida vai se aplicar a formas como dá, tem, é. Na forma mais completa, explica o acento na antepenúltima sílaba de 
algumas formas do imperfeito do indicativo, imperfeito do subjuntivo e maisque-perfeito.

Ao lado da regra de acento com sua respectiva reformulação, é proposta, também, uma regra de truncamento para apagamento da vogal temática. Em um primeiro momento, essa regra vem assim formulada:

$$
\mathrm{V} \rightarrow \varnothing /+_{-}+\mathrm{o}
$$

Sua aplicação é na primeira pessoa do singular do indicativo. Para dar conta também dos casos do presente do subjuntivo, é necessário reformulá-la para

$$
\mathrm{V} \rightarrow \varnothing /+[\text { - passado }]+\mathrm{V}
$$

O acento deve ser colocado depois da sua aplicação.

\section{Acento secundário e ritmo}

Por acento secundário deve ser entendido aquele que era inicialmente tônico e foi enfraquecido. Acento rítmico é a variação entre os graus de acento nas sílabas pré-tônicas como consequiência da tendência que se observa em português de alternar sílabas mais fortes com sílabas mais fracas. Essa tendência define o ritmo do português.

São critérios puramente fonológicos que atuam na colocação do acento rítmico. O contrário é o que pode ser constatado no acento secundário, que leva em conta o tipo de fonteira existente entre os segmentos acentuados. Ao que tudo indica, o acento secundário é, na fonologia gerativa transformacional, um argumento muito forte a favor da extensão do ciclo transformacional para o componente fonológico. $\mathrm{O}$ uso do ciclo transformacional para a análise do acento secundário pode ser exemplificado em compostos, nos casos de mesóclise, na derivação, etc.

A vantagem que Chomsky e Halle apontam para a incorporação do ciclo transformacional na fonologia pode ser entendida como um mesmo conjunto de regras, reaplicando-se em estágios sucessivos da derivação, dando conta dos diversos graus de acento, não só na palavra, mas também na oração. Nas palavras do português, a aplicação de regras cíclicas de acento é importante na colocação dos dois acentos de grau mais forte: primário ( Ac 1) e secundário ( Ac 2 ). Os demais graus ( Ac 3 e Ac 4 ) são marcados por regras não cíclicas. Um exemplo pode ser a atribuição de acento a levemente. Nesta palavra, o acento será colocado por duas aplicações da regra de acento dos nomes, pelo ciclo transformacional e por uma convenção de enfraquecimento do acento. São duas as aplicações da regra de acento em levemente. 
A primeira em relação à seqüência mais encaixada, o adjetivo leve. No segundo ciclo, à palavra completa, o advérbio levemente.

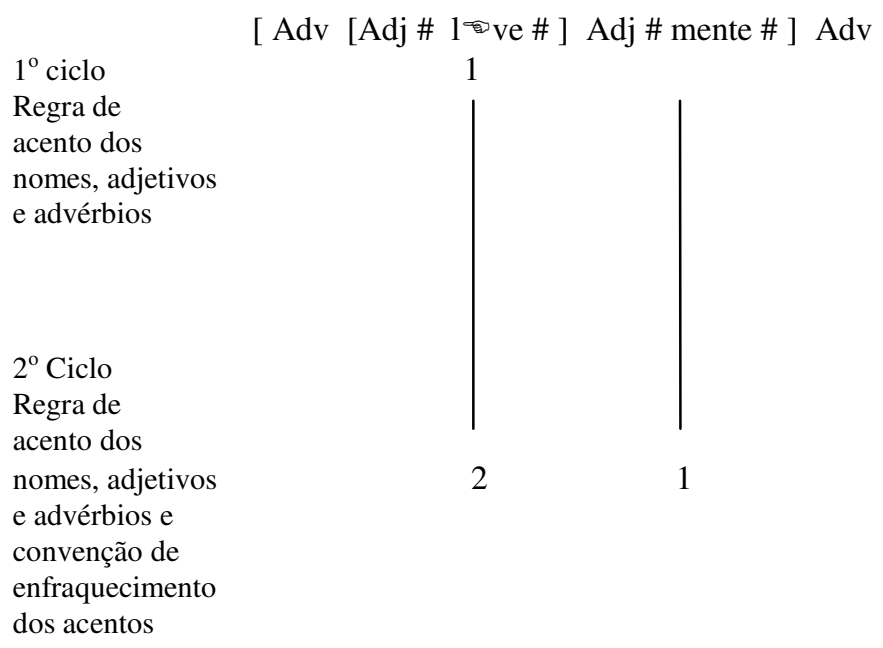

A convenção de enfraquecimento dos acentos implica na diminuição de todos os acentos, já atribuídos a sílabas da mesma sequiência, em um grau, quando se atribui acento primário a uma sílaba dentro de uma sequiência qualquer. Mais alguns exemplos da aplicação cíclica da regra de acento, podemos ter em: balõezinhos, roucamente, rouquidão.

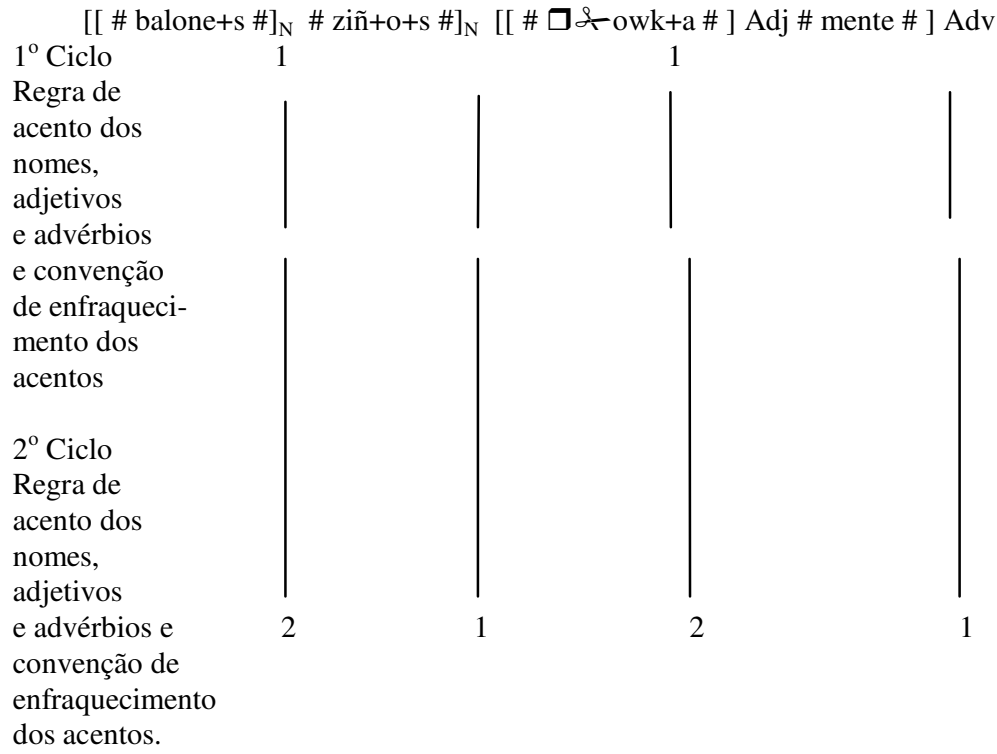




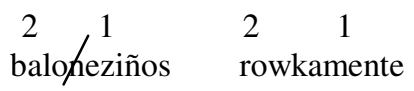

$1^{\circ}$ Ciclo

Regra de acento...
[\# rowk + edone \#] $\mathrm{N}$

Os trabalhos que se preocupam com o estudo do acento nas palavras do português observam que o uso do ciclo transformacional é restrito e que apresenta muita dificuldade em marcar o tipo de fronteira usada diante de certos sufixos, sem lançar mão de mecanismos arbitrários. Alguns dos sufixos que exigem o uso do ciclo transformacional, para a colocação adequada do acento; apresentam comportamentos especiais com relação a aspectos diversos do componente fonológico.

Por outro lado, é um problema a criação de mecanismos para apagamento de fronteiras internas, bem como indicar que tais fronteiras internas não se apagam nos nomes, nos adjetivos e nos advérbios, mas sim nas formas verbais do futuro, por exemplo.

O acento secundário, então, é marcado pela aplicação cíclica de regras e é resultado do enfraquecimento do acento primário.

Em relação às demais sílabas de cada palavra, que não receberiam o acento primário em nenhum ponto da derivação, são considerados dois graus de atonicidade: 3 e 4 . São dois graus cuja colocação na palavra é feita de forma automática, verificando-se a posição da sílaba em relação à que tem o acento primário.

Sílabas pós-tônicas sempre têm o grau 4 de acento. Em relação às pré-tônicas, há dois graus de atonicidade que obedecem a padrões de ritmo.

A noção de ritmo é proposta por Bruce E. Willis (1970). O que há de inovador, nesta maneira de atribuição de acento, é a proposta de uma regra de acento secundário baseada na noção de ritmo, de alternância na palavra entre sílabas fortes e fracas. É a seguinte a Regra de acento secundário proposta por Willis na obra citada:

"Regra de acento secundário: coloque acento de nível 2 nas sílabas cuja distância da sílaba acentuada for em múltiplos de duas sílabas. Se isso não for possível, coloque o acento de nível 2 nas sílabas adjacentes ao acento primário." (Willis 1970: 5)

A situação, em português, é mais restrita da que Willis observou no espanhol. Nesta língua, a alternância entre sílabas fortes e fracas é bem geral, pois abrange as sílabas pré-tônicas e as pós-tônicas.

Em português, a regra atingiria apenas as sílabas pré-tônicas de palavras mais extensas e não todas as palavras da língua. Considerando, então, essa idiossincrasia do português, uma proposta reformulada sobre o acento rítmico para a língua poderia ser: 
Nas sílabas que antecedem a sílaba tônica da palavra, coloque o acento de grau 3 naquela cuja distância de uma sílaba acentuada for de duas sílabas. Coloque acento de grau 3 na sílaba cuja distância de outra que também tiver grau 3 for de duas síalbas.

Todos os segmentos e fronteiras são, em princípio, não acentuados em suas representações fonológicas. Os acentos de grau 1 e 2 são atribuídos pelas regras cíclicas. O grau de acento das vogais que não tiverem ainda recebido acento primário nem secundário, pela aplicação das regras de acento e da convenção de enfraquecimento do acento, será especificado por regras não cíclicas.

Estas são a regra de acento rítmico que atribui o grau 3 de acento em algumas posições e a regra de especificação do grau de atonicidade, que, ordenada depois daquela, atribui o grau 4. A representação formal destas duas regras tem as seguintes conformações:

Regra de acento rítmico:

$$
\mathrm{V} \rightarrow[\text { Ac } 3] /-\mathrm{C}_{0} \mathrm{~V} \mathrm{C}_{0}\left[\begin{array}{c}
\mathrm{V} \\
{\left[\begin{array}{ll}
\text { Ac } & 1
\end{array}\right]} \\
{[\text { Ac } 3]}
\end{array}\right]
$$

Regra de especificação do grau de atonicidade (ordenada depois da Regra de acento rítmico:

$$
\mathrm{V} \rightarrow[\mathrm{Ac} 4] /[\overline{-\mathrm{Ac}}]
$$

A aplicação dessas regras deve dar conta de todas as variações de atonicidade em palavras como:

$$
\begin{aligned}
& \text { constituição constitucional constituinte } \\
& \begin{array}{lllllllll}
434 & 34 & 3 & 434 & 1 & 4 & 3414
\end{array}
\end{aligned}
$$

$\mathrm{Na}$ atribuição do acento, portanto, são considerados dois tipos diferentes de regras. A saber: regras que inserem o acento primário e secundário e que são cíclicas e cuja aplicação considera vários tipos de informações fornecidas pelo componente sintático; regras de atribuição dos dois graus de atonicidade, aplicadas pós-ciclicamente e que são bastante superficiais, pois já consideram a divisão silábica da representação fonética, e com aplicação bem mecânica, considerando apenas, dentro dos limites da palavra, qual é a posição da sílaba em relação à tônica.

Crítica à análise transformacional do acento feita por Botha (1971) 
A fonologia gerativa transformacional propõe o acento como não sendo uma categoria lexical distintiva e, portanto, não especificado em entradas lexicais. Esta hipótese é, para muitos, não testável. Dados concretos, observação das consequiências lógicas das regras gerais de acento que são desenvolvidas para gerar o contorno de acento de línguas particulares seriam necessários para testá-la.

O modelo Chomsky/Halle vê como exceções aparentes as conseqüências incorretas da aplicação das regras de acento. Tal posição cria uma série de problemas à proposta dos dois teóricos na medida em que não hesitam em lançar mão de artificialismos, como, por exemplo, dispositivos com o objetivo de lidar com aquelas exceções. Esses dispositivos bloqueiam o surgimento de resultados fonéticos indesejados e que são o resultado da aplicação das regras de colocação do acento. Por outro lado, incorporam-se, na representação lexical das exceções, artifícios com o objetivo único de bloquear a aplicação da regra naquelas situações em que ela gerasse como resultado, uma representação fonética indesejada. A representação lexical torna-se, por obra de tais artifícios, modificada de tal forma que a aplicação da regra de acento produz sempre o resultado desejado. Conseqüentemente, surge a necessidade de regras especiais, que se adicionam à gramática, com a função de apagar o artifício tão logo tenha este cumprido o seu papel e, antes, que ele possa ser realizado foneticamente. Torna-se evidente que se trata de uma estratégia protecional/protetora em relação à regra de acento, na medida em que impede uma situação de teste à regra, impedindo, outrossim, a apresentação de contra-exemplos.

Chomsky/Halle (1968), afirmam:

\begin{abstract}
"é bastante óbvio que muitas das regras fonológicas da língua terão exceção que, do ponto de vista da descrição sincrônica, serão bastante arbitrárias (...). A fonologia, sendo essencialmente um sistema finito, pode tolerar alguma falta de regularidade (exceções podem ser memorizadas); sendo um sistema altamente intrincado, resultante (...) da atuação conjunta de diversos processos históricos, espera-se que uma certa margem de irregularidade persistirá em quase todos os aspectos da descrição fonológica."
\end{abstract}

Aceitam os autores exceções a uma regra fonológica e a partir de suas afirmações é possível definir uma classe de exceções a uma regra fonológica como o conjunto de palavras cujo comportamento irregular, no tocante à regra, é devido à atuação de processos históricos os mais variados. É claro que estamos diante de exceções do ponto de vista sincrônico apenas.

Mesmo aceitando as referidas exceções como devidas à atuação conflitante de processos históricos variados e não as analisando como contraexemplos às regras de acento, permanece a explicar a estratégia empregada, com o objetivo claro e específico de evitar resultados indesejados pela aplicação das regras. 
Uma lingüística de natureza taxonômica questionará, em sua totalidade, a validade de um procedimento que bloqueie a aplicação de uma regra porque esta traz, em sua conformação, segmentos fonológicos artificiais na representação fonológica e que não virão a ter realização fonética alguma. Se fosse uma outra perspectiva, que não a fonologia gerativa transformacional, os artifícios empregados constituiriam o aspecto de maior suspeição. E isto em especial quando se considera que, depois de terem cumprido sua função, são eles removidos, apagados por regras especiais.

A situação, porém, é totalmente outra dentro do contexto da fonologia gerativa transformacional. Criticar a estratégia, sob a alegação de que a representação fonológica é abstrata em excesso, é uma posição inválida e, até certo ponto, desprovida de sustentação teórica. Chomsky e Halle rejeitam, explicitamente, a necessidade de uma correspondência de um-a-um entre os segmentos da representação fonológica e os da representação fonética. O que importa, e exatamente do ponto de vista teórico, é o custo total da gramática que possa vir a ser gerado pela abstração das representações lexicais. Estas, se demasiado abstratas, tornariam a relação entre o seu nível fonético muito indireta. Por consequiência, haveria um aumento do custo total da gramática exatamente por causa da exigência de regras adicionais que relacionassem os níveis de representação. Sendo assim e do ponto de vista de uma análise interna da gramática gerativa transformacional, nenhum problema na postulação de segmentos subjacentes que não têm correspondência na representação fonética. Não há sentido criticar uma estratégia que postule segmentos abstratos. É característica essencial do modelo. $\mathrm{O}$ que se pode questionar em um determinado momento é a escolha de um modelo que permita tal nível de abstração. E isso desde um ponto exterior às análises feitas pela fonologia gerativa transformacional.

A crítica de Botha se dirige à natureza $a d$ hoc na série de decisões que são tomadas quando da postulação de um segmento subjacente, bem como

$\operatorname{esco} * * * * * * * * * * * * * * * * * * * * * * * * * * * * * * * * * * * * * * * * * * * * * * * * * * * * * * * * * * * * * * * * *$

***************************************************************************** **************************************************************************** ***************************************************************************** *************************************************************************** 
$* * * * * * * * * * * * * * * * * * * * * * * * * * * * * * * * * * * * * * * * * * * * * * * * * * * * * * * * * * * * * * * * * *$
$* * * * * * * * * * * * * * * * * * * * * * * * * * * * * * * * * * * * * * * * * * * * * * * * * * * * * * * * * * * * * * * *$ fonológicas.

Ainda segundo Botha, a teoria da fonologia transformacional apresenta alguns dispositivos que são protegidos de uma situação real de teste que leve à sua confirmação ou negação. Entre esses "protegidos", há dois que interessam à questão do acento: o ciclo transformacional na fonologia e as regras de explicação do processo acentual. Explicitando, dir-se-á que o ciclo transformacional é protegido por dois dispositivos de bloqueio: regras de reajuste e o princípio para interpretação de representações fonéticas que anula, ao nível fonético, distinções de acento não desejadas.

Quanto à proteção do fenômeno acentual, vê-se que os dispositivos para a explicação do acento são bloqueados, protegidos ainda por uma situação artificial, ou seja, estratégia de modificação ad hoc das representações lexicais.

Exemplificando, é possível dizer que, em uma proposta de acento do português, seriam dispositivos de bloqueio: um /e/ final nas representações fonológicas dos nomes e infinitivos verbais, a regra de apagamento de fronteiras internas nas formas verbais do futuro; o uso das regras de reajuste para mudar as fronteiras anteriores a certos sufixos derivacionais, etc., etc.

O próprosito único que, segundo Botha, existe na adoção de dispositivos de bloqueio é de proteger a teoria de evidências contrárias, mesmo que, para tanto, tais dispositivos sejam adotados de forma ad hoc. Há um desencorajamento em reconsiderar algumas das hipóteses básicas da teoria, o que, é obvio, a impede de continuar a desenvolver-se.

ANÁLISE DO ACENTO SEGUNDO A FONOLOGIA GERATIVA NATURAL

\section{A fonologia gerativa natural}

Os dispositivos analíticos da fonologia gerativa transformacional tais como a técnica de formalização, a representação lexical, as regras fonológicas, o uso dos traços distintivos para especificar os segmentos, etc., continuam tendo seu lugar na proposta de mudança que vem logo a seguir sob o nome de Fonologia gerativa natural. A grande busca que se nota é em direção de um maior realismo.

E com este realismo se quer colocar o assim chamado falanteouvinte ideal chomskyano mais na realidade. A partir, então, de tal propósito, vão surgir limitações à abstração das representações fonológicas. Requisitarse-á a substituição de uma medida de avaliação baseada na simplicidade formal por uma outra baseada na variação dialetal, na mudança histórica, na capacidade articulatória dos indivíduos e na aquisição da linguagem. Tudo 
isso está a representar uma medida de avaliação mais lingüística e menos matemática.

As tendências que surgiram na direção de reformular a fonologia gerativa transformacional foram diversas e, por isso mesmo, não apresentavam, num primeiro momento, uma uniformidade. No entanto, houve uma linha de pesquisa que trouxe consideráveis avanços em busca do já mencionado realismo lingüístico. Estamos nos referindo à fonologia gerativa natural. Seus teóricos mais representativos são Theo Vennemann e Joan Hooper.

Três aspectos básicos caracterizam esse modelo como diferente de Chomsky/Halle (1968). Vejamo-los.

1.Restrições incorporadas no modelo limitam a abstração das representações lexicais. Em termos práticos, grau de abstração deve ser entendido como a diferença entre a representação incluída no léxico e as formas fonéticas correspondentes.

2.A função atribuída às regras fonológicas é alterada. Elas não mais serão responsáveis pela ligação entre a representação lexical e a fonética, passando a ser consideradas, em grande parte, como afirmações redundantes sobre as representações lexicais. Reconhecem-se no modelo, tipos diferentes de regras no componente fonológico: regras fonológicas, morfo-fonêmicas e de relacionamento lexical (via-rules).

3.Há o deslocamento do critério de simplicidade formal nas descrições como medida de avaliação. Considerações que envolvem naturalidade fonética com base em propriedades articulatórias, acústicas e perceptuais dos sons, substituem a assim chamada medida de simplicidade.

Uma fundamental proposta do modelo é a assim-chamada condição forte de naturalidade, cujo autor, Vennemann (1971), assim define:

"A condição forte de naturalidade afirma que representações lexicais de partes não alternantes de morfemas são idênticas a suas representações fonéticas, e que representações lexicais de raízes são idênticas a um dos alomorfes do paradigma, mais um conjunto (freqüentemente vazio) de regras de supleção" (Vennemann 1971)

É esta condição que procura solucionar o problema das abstrações nas representações lexicais, já que ela impõe fortes limitações à abstração nas representações subjacentes. A consequiência de tal restrição é que as representações subjacentes de morfemas devem ser idênticas à sua representação fonética. E no caso de morfemas alternantes? É escolhida uma das formas para a representação lexical e as outras são derivadas dela por meio de regras de supleção. Não são admitidas representações subjacentes 
com características de um dos morfemas alternantes e, ao mesmo tempo, com características de outras alternâncias.

Percebe-se, então, que o léxico é composto por formas que contêm um alto grau de redundância que é, por sua vez, descrita nas regras fonológicas. Estas são, também, regras gerativas, aplicando-se à produção de formas novas quando seu ambiente for satisfeito no curso de uma derivação.

É possível que regras da fonologia gerativa natural sejam, do ponto de vista da formulação, mais complexas do que as regras da fonologia gerativa transformacional. A que se poderia atribuir este custo aparente? Ao que tudo indica, ao fato de eliminar-se a possibilidade de ordenação extrínseca. Segundo Hooper (1973), não há um custo, mas um ganho porquanto a complexidade na formulação estará revelando um grau de explicação maior, uma vez que a regra traz na sua formulação a motivação fonética da ocorrência do processo descrito. Isto nos leva a entender que, no tocante a medidas de avaliação para gramáticas possíveis de uma língua, a fonologia gerativa natural substitui o critério de simplicidade pelo de naturalidade, isto é, busca-se na formulação das regras apresentar, explicitamente, a motivação fonética para sua aplicação.

O modelo gerativo natural distingue dois tipos de regras: as fonológicas e as morfofonêmicas. Enquanto as primeiras podem ser formuladas em termos fonéticos, sem referência a informações sintáticas, semânticas ou morfológicas nem a fronteiras gramaticais, as segundas fazem referência a outras informações não puramente fonéticas na sua formulação. As regras morfofonêmicas mudam traços fonológicos, assim como as regras fonológicas, mas não o fazem por um condicionamento puramente fonético. Aplicam-se, em vez disso, a categorias ou classes morfológicas.

Há ainda, por considerar, um terceiro tipo de regra reconhecido pelo componente fonológico da gramática gerativa natural e de uma natureza bem diversa das duas regras anteriores. São as regras de relacionamento lexical. São regras que procuram descrever um aspecto do conhecimento real que alguns falantes têm do léxico da língua. É um dispositivo que deve refletir o conhecimento que o falante tem da língua, mostrando que ele é capaz de relacionar, fonológica e semanticamente, duas representações lexicais. Se o falante relaciona foneticamente os dois itens, supõe-se que ele conheça uma regra que lhe indica uma correspondência entre, por exemplo, o $\triangle$ de noite e o \& de noctivago. Seu conhecimento é expresso na gramática através de uma regra cuja conformação é assim:

\section{$\mathrm{K} \leftrightarrow \mathrm{Y}$}

O formato da seta, dupla, está indicando não haver uma direcionalidade única no processo. Não há a suposição que uma das formas seja derivada da outra. É importante salientar que as regras de relacionamento lexical variam de uma falante a outro. Alguns falantes as conhecem, outros não. Esta variabilidade, então, permite que sejam mostradas diferenças de 
competências, indicando a variação do conhecimento da língua por falantes diversos.

\section{O acento na fonologia gerativa natural}

Neste modelo, as regras que vão explicar a posição do acento estarão sempre entre as regras morfofonêmicas. Isto significa, então, que elementos ligados às questões de acento analisam-se, na fonologia gerativa natural, entre os processos morfofonêmicos.

$\mathrm{O}$ ciclo transformacional não é incorporado à fonologia gerativa natural. Para certos autores, Abaurre (1974), Rudes (1976) existe o ciclo nesse modelo, mas totalmente diverso de como empregado na fonologia gerativa transformacional, já que sua função é de derivar uma representação fonética de outra e não a de derivar uma representação fonética de uma representação fonológica a ela subjacente.

É um dos objetivos da fonologia gerativa natural que a descrição dos processos gramaticais já inclua sua explicação. Essa abordagem dos fatos coloca questões mais ou menos complexas em relação ao acento. Por exemplo, o acento nos nomes em português tem duas possibilidades de análise, ambas compatíveis com os dados e com os princípios da fonologia gerativa natural. Em qual das duas descrições está a explicação incluída na própria descrição? A resposta à pergunta é observar se a posição do acento nos nomes leva em conta sua constituição fonológica ou morfológica. Colocado de outra forma, leva em conta a constituição das sílabas ou a organização dos morfemas? A questão quanto aos verbos é de que a posição do acento deve partir dos morfemas, componentes das formas verbais. $\mathrm{O}$ mesmo pode ser afirmado em relação aos nomes? Seria melhor uma análise que levasse em conta também os morfemas? Uma resposta deve considerar o aspecto explicativo da análise. E é exatamente por causa disso que é preciso esclarecer se os dois processos de acentuação são, realmente, semelhantes.

\section{Uma análise do acento nos nomes baseada na força da sílaba}

\section{A sílaba em português}

A estrutura silábica, no português, se caracteriza pela variedade de padrões encontrados. E, de imediato, é preciso decidir qual o tipo de sílaba que é relevante tanto para a posição do acento quanto para outros processos da fonologia da língua.

De modo geral, as sílabas apresentam a seguinte forma possível, onde os parênteses indicam opcionalidade:

$$
\left(C_{1}\right)\left(C_{2}\right)(G) V(G)\left(C_{3}\right)\left(C_{4}\right)
$$


A forma apresentada é de caráter de possibilidade, não quer dizer que se encontrem, em português, todos os elementos constituintes ao mesmo tempo. Os padrões silábicos mais complexos são do tipo: CCVC ou CVCC (transporte, perspectiva). Alguns padrões silábicos ocorrem com uma frequiência maior do que os demais. Seriam: CV e CVG.

Segundo os analistas da língua, é exatamente para os elementos que constituem esses dois tipos de sílabas que o português não apresenta restrição alguma de ocorrência, isto é, qualquer consoante pode ocorrer no início da sílaba, qualquer vogal pode ser centro silábico e qualquer glide pode ocorrer junto a qualquer vogal (A seqüência $\mathrm{Y}$ é a exceção).

\section{Sílaba e acento}

O acento, nos nomes em português, leva em conta a constituência das sílabas. Em especial a da última sílaba da palavra que, se for forte, será acentuada. Assim sendo, palavras terminadas em [ $\square \downarrow$ ] [ h ], nasal ou ditongo serão acentuadas na última sílaba, demonstrando uma situação de regularidade quanto à acentuação na língua.

Tendo como ponto de partida a relação que existe entre estrutura silábica e acento, podemos fazer as seguintes afirmações:

(a) O acento localizar-se-á na última sílaba, sendo essa forte.

(b) O acento localizar-se-á na penúltima, sendo fraca a última sílaba.

Estamos diante de duas regras: acentuação na última sílaba e acentuação na penúltima sílaba. A formalização da primeira terá a configuração seguinte:

$$
\mathrm{V} \rightarrow[\text { Ac 1 }] /-\left[\begin{array}{c}
{[+ \text { nasal }]} \\
{\left[\begin{array}{l}
\mathrm{x} \text { consonantal } \\
\mathrm{x} \text { vocálico }
\end{array}\right]}
\end{array}\right] \# \text { N, Adj, Adv }
$$

A segunda regra terá a seguinte conformação:

Acento na penúltima sílaba.

$\mathrm{V} \rightarrow[$ Ac 1 ] / — \# ( C ( G ( C ) ) ) V\# ] N, Adj, Adv.

São exceções a essa regra: palavras que têm acento na última sílaba, embora esta seja fraca, ou seja, terminada em vogal ou /s/: rapaz, inglês, café, cipó, etc.; palavras que têm acento na antepenúltima sílaba: árvore, tímido, médico. Nestes exemplos, nem a penúltima nem a última sílaba podem ser fortes.

Por serem pouco numerosas as palavras dessas duas classes, são elas tratadas como exceções.

Uma análise do acento baseada na organização dos morfemas na palavra 
Hooper (1973) propõe que o acento nos verbos do espanhol é determinado pelas características dos morfemas que constituem as formas verbais. Marca-se, então, o acento nos verbos a partir de referência à raiz verbal e aos morfemas que marcam os tempos do verbo.

Este tipo de análise pode ser proposto, também, para o português, pois, ao que tudo indica, a análise que relaciona, nos verbos, a posição do acento com os morfemas parece ser a única que, dentro do modelo da fonologia gerativa natural, se adequa para dados do português.

\section{Análise do acento nos verbos}

A fonologia gerativa natural propõe, então, que todo o condicionamento para a posição do acento nos verbos seja de natureza, de ordem morfológica. Isso implica, portanto, no uso de traços morfológicos como regra geral, em todos os casos, e não somente em exceções.

O que estará importando, nesta proposta de análise, é a relação entre a sílaba acentuada e a raiz verbal ou sua relação com as marcas de modotempo-aspecto e número-pessoa.

A análise da fonologia gerativa natural é restrita àquelas características que são transparentes na representação fonética e parte da hipótese de que um falante da língua só dispõe de dados fonéticos e vai formular apenas hipóteses que se relacionem, diretamente, a esses dados. Sendo assim, a observação mais geral é de que, para cada um dos tempos verbais do português, o acento é colocado na mesma sílaba, contada não em relação ao final da palavra, mas à raiz verbal.

Os morfemas raiz (R), vogal temática (VT), marca de modo-tempoaspecto (MTA), marca de número-pessoa (NP) dispostos, em uma determinada seqüência, expressam a constituência das formas verbais.

Temos, portanto:

\section{[ [ ] R [ ] VT [ ] MTA [ ] NP ] V}

Nas formas verbais, o acento é totalmente previsível e as regras formuladas, propostas, dentro do modelo, são uma hipótese sobre o conhecimento que o falante de português pode vir a ter a respeito do acento nelas.

Pode-se falar em uma regra, segundo a qual o acento é colocado na vogal temática. As marcas de modo-tempo-aspecto (futuro do presente e futuro do pretérito) ou informações fornecidas, conjuntamente, pelas marcas de modo-tempo-aspecto e de número-pessoa condicionam as exceções a essa regra.

De um modo geral, as regras para o acento nos verbos conseguem descrevê-lo em todas as formas verbais. Consideram-no previsível e usam apenas traços morfológicos como relevantes para sua posição em 
determinadas sílabas. Para ilustrar essa afirmação, apresentamos as regras de acento tal como propostas em Costa (1978).

\section{O acento nos nomes}

A proposta que Hooper/Terrel (1976) fazem para uma análise do acento nos nomes baseia-se numa relação entre estes e os morfemas que os constituem. A análise que apresentam para o espanhol mostra que os nomes são constituídos por uma raíz seguida, opcionalmente, de uma vogal de classe e, nas formas do plural, de um morfema de plural. O mesmo pode ser dito em relação ao português onde são consideradas três vogais de classe ou vogais temáticas: $/ \sigma /, / \mathrm{o} / \mathrm{e} / \mathrm{e} /$. Ao contrário dos verbos onde as vogais temáticas são usadas para dividi-los em três grupos, ou conjugações, nos nomes a função da vogal temática não é tão clara. Duas delas, /ర/ e /o/ relacionam-se com uma variação de gênero, predominando formas femininas entre os que têm a vogal temática $/ \sigma /$, e predominando formas masculinas entre os que têm a vogal temática $/ \mathrm{o}$.

Pode-se dizer que é uma questão de predominância, não de absoluta correspondência. Quanto aos nomes com a vogal temática /e/, pode-se constatar que alguns pertencem à classe masculina e outros à feminina.

Um estudo prévio do gênero, em português, é importante para a análise das vogais temáticas. Segundo Costa (1978), essas vogais estão muito mal estudadas, em português, o que gera problemas para a análise do acento que se baseie nos morfemas que constituem os nomes.

Transpor para o português a análise Hooper/Terrel, de modo paralelo ao que propõem para o espanhol, significa considerar, por exemplo, que o sufixo -(z)inho é -(z)inh-, e que a vogal temática é deslocada do nome para o sufixo. Ao que tudo indica, não é uma boa análise para o português. Tendo, então, como base a estrutura raiz e vogal temática para os nomes, Hooper/Terrel propõem a colocação do acento, por uma regra geral, na última vogal da raiz, estabelecendo, portanto, uma formulação que dá conta do acento em todas as palavras oxítonas bem como das paroxítonas que terminem em uma vogal temática ou, então, em morfema de feminino.

As palavras que apresentam o acento marcado na penúltima vogal da raiz (proparoxítonas e paroxítonas terminadas em consoantes ou ditongos) têm a última vogal da raiz marcada com um diacrítico. Hooper e Terrel indicam esta situação por meio de um $X$ que pode ser usado, também, na configuração das regras do português. A proposta formalizada vai apresentar a seguinte configuração, como regra de acento nos nomes:

$$
\left.\mathrm{V} \rightarrow[\mathrm{Ac} 1] /-\left(\mathrm{C}_{\mathrm{o}} \mathrm{V}_{\mathrm{x}}\right) \mathrm{C}_{\mathrm{o}}\right] \mathrm{R}
$$

Esta regra, tal como está, vai dar conta de casos como: órgão, árvore, revólver, número. Sem o diacrítico e, na sua forma mais simples, a regra explica casos como: café, irmão, tomate, jardim, rapaz, gato. 
A faceta problemática desta análise está na divisão entre raiz e vogal temática. Surge a necessidade de se concluir que é uma distinção relevante para outros aspectos da fonologia da língua, a fim de que se possa optar por esta análise como uma que mais bem se adeque aos dados. De qualquer modo, a análise mostra que há alguma arbitrariedade na posição do acento, mas que tal arbitrariedade é pequena, porquanto existe regularidade na maior parte dos casos.

\section{O acento na derivação}

As análises do português mostram que em palavras que tenham um sufixo derivacional, o acento principal deve estar em uma das sílabas desse sufixo. Os mesmos critérios utilizados para os nomes podem ser empregados, para decidir em qual das sílabas o acento deve estar.

Esse tipo de palavras pode ser analisado de duas maneiras quanto ao acento principal: (a) considerar como fator determinante para a posição do acento a estrutura silábica da última sílaba do sufixo e (b) indicar que, nas palavras que têm sufixos derivacionais, esse sufixo (exceto a vogal temática ou morfema de feminino que ele eventualmente apresentar) está incluído na raiz, e que a última vogal da raiz deve ser acentuada, a menos que seja marcada com um diacrítico; nesse caso, o acento irá para a penúltima vogal.

No que se refere à posição do acento principal, os sufixos derivacionais têm um comportamento uniforme, o que não acontece em relação ao acento secundário. Para dar conta dessa situação, o modelo da fonologia gerativa natural dispõe de um mecanismo que explica o comportamento diverso no tocante à manutenção do acento principal da palavra primitiva. Para bem entendermos o problema, temos de considerar dois tipos de dados no português que envolvem as palavras formadas com um sufixo derivacional.

Vejamos, então, o primeiro grupo de tais palavras no qual se incluem leveza, rapidez, movimento, realismo, etc., isto é, com os sufixos -eza, -ez, -mento, -ismo. Este grupo de palavras tem como característica especial, e única, em relação ao acento, a circunstância de que ele deve ser colocado sobre o sufixo.

O segundo grupo de sufixos derivacionais é mais restrito, uma vez que contém, apenas, três sufixos: -(z)inho, -mente, -íssimo. A sílaba tônica da raiz, nas palavras formadas com esses sufixos, não se torna átona, apenas passa do nível de acento 1 para 2, enfraquecendo, portanto. Exemplos podem ser:

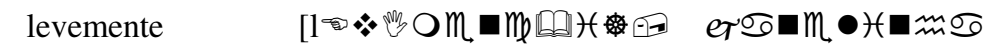
[Hㅁ] 
Se a análise de Câmara Jr. e a do modelo da fonologia gerativa transformacional agrupam esses casos como composição, a fonologia gerativa natural oferece uma outra possibilidade de análise que se baseia nos conceitos de morfologia produtiva e morfologia lexicalizada. Hooper (1973) tem como posição que as palavras contendo morfemas lexicalizados sejam incluídas no léxico como itens separados, por um lado, e, por outro, que uma palavra derivada por processos produtivos não seja alistada no léxico. Para o modelo em questão, surge como possibilidade de explicação o fato de que o falante, quando utiliza uma palavra derivada com um dos três sufixos do segundo grupo, mantém consciência de que a palavra primitiva à qual o referido sufixo foi acrescentado é um item lexical distinto que mantém seu acento. Por outro lado, este item lexical distinto está sujeito a certas regras que se aplicam, caracteristicamente, em final de palavras.

A derivação produtiva é um processo usado, conscientemente, pelo falante, o que explicaria a manutenção do acento da palavra primitiva. Tal afirmação significa que o falante tem consciência de que está combinando dois elementos distintos, cada um com seu acento próprio. Para Hooper, são as palavras, e não os morfemas da língua, que constituem o material registrado no léxico da gramática gerativa natural. Em se tratando de derivação produtiva, o léxico apresenta as palavras primitivas e, em separado, os sufixos produtivos. À competência dos falantes da língua cabe a combinação dos elementos dos dois conjuntos por meio da aplicação das regras de derivação.

Essa é uma explicação adequada ao que se observa em relação aos sufixos -mente, -(z)inho $e$-íssimo. É um processo cuja explicação seria: o falante aplica certas regras às palavras primitivas, incluindo a regra de acento, combina essas palavras com o sufixo e, a seguir, aplica a mesma regra de enfraquecimento do acento tônico que ocorre em diversos casos de composição ou em seqüências de palavras.

\section{CONCLUSÃO}

$\mathrm{Na}$ perspectiva geral do (dois) modelo da fonologia gerativa transformacional, o que se pode observar é a existência de muitos problemas na análise do acento em português. A maioria, ou a totalidade, de tais problemas são o resultado de um poder excessivo que o modelo concede e/ou permite aos seus dispositivos de análise. Tome-se como exemplo a questão da busca de uma maior simplicidade formal nas descrições, na formulação das regras. Uma posição deste tipo gera um tão grande distanciamento dos dados fonéticos que torna praticamente impossível reconhecer-se a análise como sendo a descrição da competência de um falante da língua.

Estudiosos do acento, em português, afirmam ser esta faceta da língua a que põe em evidência as falhas do modelo transformacional mais do que quaisquer outros aspectos da fonologia da língua. O modelo compromete, pela própria organização dos dispositivos de análise, as indagações que se 
façam a respeito da natureza do acento. Em princípio, a resposta oferecida por essa teoria é uma só: o acento é previsível por regras. Não obstante, os dados podem não se ajustar com tal pressuposto. Surgirão, conseqüentemente, várias maneiras de explicação das diferenças entre nível fonético e representação fonológica. Um modelo teórico que aceita tais mecanismos permitirá que se duvide das respostas fornecidas sobre a natureza do acento em uma língua qualquer e, no caso específico, do português.

Quanto à fonologia gerativa natural, a pretensão é de que para um conjunto de dados haja apenas uma análise possível. Por outro lado, a explicação dos processos analisados já deve estar incluída na própria descrição. O objetivo do modelo é a descrição de processos morfofonêmicos, o que, de certo modo, não foi atingido. A questão da morfologização é, em si mesma, um problema, o que leva a um questionamento da própria proposta quando se trata de descrever a morfologização de algum processo. De qualquer modo e considerando duas análises possíveis para um mesmo conjunto de dados bem como a inexistência de uma medida de avaliação que possibilite optar por uma ou por outra, é preciso refletir sobre o problema da morfologização dos processos em uma língua.

\section{BIBLIOGRAFIA}

ABAURRE, M. B. M. Identidade de representação básicas e fatores de diferenciação superficial no componente fonológico de línguas cognatas. Dissertação de Mestrado. UNICAMP, 1973.

ABAURRE, M. B. M. Some problems of portuguese phonology in the light of NGP and the revised strong naturalness condition. Buffalo, SUNY, ms, 1974.

ABAURRE, M. B. M. Some cases of plural formation in portuguese: a natural approach. Buffalo, SUNY, ms, 1974.

BATELLI, S. H. Aspectos derivacionais em português. Dissertação de Mestrado. PUCCAMP, 1975.

BOTHA, R. P. Methodological aspects of transformational generative phonology. Mouton, The Hague, 1971.

CAMARA JR., J. M. Estrutura da língua portuguesa. Petrópolis, Editora Vozes, 1970.

CHOMSKY, N. \& M. HALLE. The sound pattern of English. New York, Harper \& Row, 1968.

COSTA, I. B. O acento em português: estudo de algumas mudanças no modelo da fonologia gerativa. Dissertação de Mestrado. UNICAMP, 1978.

GARDE, P. L'Accent. Paris, Presses Universitaires de France, 1968. 
HARRIS, J. W. Spanish phonology. Cambridge, Mass., The MIT Press, 1969.

HARRIS, J. W. Syllable structure and stress in Spanish. Cambridge, Mass., The MIT Press, 1983.

HOOPER, J. B. Aspects of natural generative phonology. PhD Thesis, The University of California at Los Angeles, 1973.

HOOPER, J. B. \& TERREL. Stress assignment in Spanish: a natural generative analysis. In: Glossa, 10, 1976.

HYMAN, L. M. Phonology: theory and analysis. New York, Holt, Rinehart \& Winston, 1975.

LEITE, Y. Portuguese stress and related rules. $\mathrm{PhD}$ Thesis, The University of Texas at Austin, 1974.

PIKE, K . L. Phonemics. Ann Arbor, University of Michigan Press, 1949.

RUDES, B. A. Lexical representation and variable rules in natural generative phonology. In: Glossa, 10, 1976.

TROUBETZKOY, N. S. Principes de phonologie. Paris, Éditions Klincksieck, 1970.

VENNEMANN, T. Natural generative phonology. Trabalho apresentado na Annual Meeting of The Linguistic Society of America. Saint Louis, Missouri, 1971.

WILLIS, B. E. Stress assignment in Spanish. In: SADOCK, Jerrold M.; VANEK, Antony L. (eds.) Studies Presented to Robert B. Less by his Students. Edmonton-Champaign: Linguistic Research Inc., 1970. 